Original Research Paper

\title{
Penentuan Bonus Karyawan dengan Menggunakan Metode Analytic Network Process di PT. Global Harvest Precision Engineering
}

\author{
Suliza Apandi ${ }^{1}$, Okta Veza ${ }^{1}$, Sanusi Majid ${ }^{2}$, Pratiwi $^{3}$, Ismail Yusuf Panessai ${ }^{1}$ \\ ${ }^{1}$ Program Studi Teknik Informatika, Universitas Ibnu Sina Batam. Indonesia. \\ ${ }^{2}$ Program Studi Teknik Industri, Universitas Ibnu Sina Batam. Indonesia. \\ ${ }^{3}$ PT. Batam Cable Vision. Batam. Indonesia.
}

Article History
Received:
10.01 .2020

Revised:
11.02 .2020
Accepted:
30.03 .2020
*Corresponding Author:
Suliza Apandi
Email:
sulizaapandi11@gmail.com

This is an open access article, licensed under: $\mathrm{CC}-\mathrm{BY}-\mathrm{SA}$
Abstrak: Penelitian ini bertujuan merancang sistem pendukung keputusan dalam menentukan karyawan penerima bonus pada PT. Global Harvest Precision Engineering yang beralamat di lot 21 citra buana III Batam Centre Kepulauan Riau. Dikarenakan tidak adanya sistem pendukung keputusan yang membantu dalam menentukan karyawan penerima bonus, sehingga dibutuhkannya perancangan sistem pendukung keputusan. Data pada sistem pendukung keputusan penetuan bonus karyawan ini diperoleh dari data karyawan dari bulan januari sampai dengan Juni 2019, yang terdiri dari nama, tempat tanggal lahir, alamat dan jenis kelamin beserta data absen perbulan. Model sistem yang digunakan Data Flow Diagram (DFD). Sistem pendukung keputusan dirancang berbasis web mobile dengan menggunakan bahasa pemograman Hypertext Preprocessor (PHP) dan database MySQL. Teknik Penelitian kuantitatif, dengan mengumpulkan data-data hasil perhitungan. Penelitian menghasilkan aplikasi sistem pendukung keputusan berbasis web mobile dalam menentukan karyawan penerima bonus. Pengujian dalam aplikasi menggunakan blackbox.

Kata Kunci: Sistem Pendukung Keputusan, Web Seluler, Proses Jaringan Analitik.

Determination of Employee Bonuses Using the Analytic Network Process Method at PT. Global Harvest Precision Engineering

Abstract: This study aims to design a decision support system in determining employee bonus recipients at PT. Global Harvest Precision Engineering which is located at lot 21 Citra Buana III Batam Center Riau Islands. Due to the absence of a decision support system that helps in determining the bonus employee, a decision support system design is needed. Data on the decision support system for determining employee bonuses is obtained from employee data from January to June 2019, which consists of name, place of birth date, address and gender along with monthly absence data. The system model used is Data Flow Diagrams (DFD). Decision support system is designed based on mobile web using the Hypertext Preprocessor (PHP) programming language and MySQL database. Quantitative research techniques, by collecting data from calculations. The research resulted in the application of a web-based mobile decision support system in determining employee bonus recipients. Inapp testing uses a blackbox.

Keywords: Analytic Network Process, Decision Support System, Mobile Web. 
Suliza Apandi, Okta Veza, Sanusi Majid, Pratiwi, Ismail Yusuf Panessai.

Penentuan Bonus Karyawan dengan Menggunakan Metode Analytic Network Process di PT. Global Harvest Precision Engineering.

Journal of Engineering, Technology \& Applied Science, vol. 2, no. 1, pp. 51-58, April 2020. DOI: 10.36079/lamintang.jetas-0201.94

\section{Pendahuluan}

Berdasarkan hasil dari observasi bersama manajer di PT. Global Harvest Precision Engineering, untuk membantu dalam pengambilan sebuah keputusan pemberian bonus kepada karyawan perusahaan. Dibutuhkan sebuah sistem yang dapat membantu admin ataupun manajer untuk mengambil keputusan. Sebagaimana ditentukan dalam Pasal 70 ayat (1) UU No. 40 Tahun 2007 tentang Perseroan Terbatas (UU PT). Berdasarkan Peraturan Menteri No 78 Tahun 2015 tentang Pengupahan Pasal 6 dan dalam surat edaran menteri tenaga kerja SE-07/MEN/1990 untuk memberikan bonus yang merupakan pemberian di luar upah dari keuntungan perusahaan.

Decision Support System (DSS) adalah Sistem berbasis komputer interaktif yang membantu para pengambil keputusan untuk menggunakan data dan berbagai model untuk memecahkan masalah yang tidak terstruktur. Sistem Pendukung Keputusan (SPK) atau Decision Support System (DSS) merupakan suatu pendekatan atau metodologi untuk mendukung pengambilan keputusan.DSS menggunakan Computer Base Information System (CBIS) yang fleksibel, interaktif dan dapat diadaptasi yang dikembangkan untuk mendukung solusi bagi masalah manajemen spesifik yang tidak terstruktur [1].

\section{Metode Penelitian}

\subsection{Metodologi Penelitian}

Metode yang digunakan dalam penelitian ini adalah metode kualitatif, tata cara bagaimaa suatu penelitian dilaksanakan. Metode penelitian merupakan cara yang digunakan oleh penelitian dalam mengumpulkan data penelitiannya, seperti wawancara, observasi, tes maupun dokumentasi.

\subsection{Metode Pengumpulan Data}

Metode pengumpulan data yang diguakan dalam penelitian ini, diantaranya:

1. Wawancara

2. Observasi

3. Studi Pustaka

4. Jenis Data

a. Data Primer

b. Data Sekunder

\subsection{Metode Perancangan Sistem}

Metode yang digunakan dalam perancangan sistem ini adalah Model Decision Support System (DSS) Analytic Network Process (ANP) dengan tahapan sebagai berikut [2] [3] [4] [5] [6]:

1. Perancangan Sistem

2. Analisis Sistem

3. Perencanaan Sistem

4. Pengujian Sistem

5. Implementasi Sistem

\subsection{Kerangka Pemecahan Masalah}

Tahapan dan ruang lingkup penelitian yang akan dilakukan meliputi beberapa tahapan dengan mengacu pada pemecahan masalah berikut ini [7] [8] [9] [10]:

1. Menentukan Pokok Masalah

Kerangka pemecahan masalah dimulai dari Penetuan Pokok Masalah dan Tujuan laporan kerja praktek sehingga penulis dapat mengetahui apa yang diperlukan dalam melakukan perancangan

2. Mengumpulkan Data

Setelah mengetahui pokok masalah dan tujuan, selanjutnya penulis melakukan pengumpulan data berupa data primer dan data sekunder yang akan digunakan sebagai bahan dalam membuat perancangan.

3. Analisa Data

Sebelum melakukan pengolahan data, data primer dan data sekunder yang telah dikumpulkan dianalisi terlebih dahulu sehingga akan mempermudah dalam melakukan pengolahan data.

4. Pengolahan Data 
Suliza Apandi, Okta Veza, Sanusi Majid, Pratiwi, Ismail Yusuf Panessai.

Penentuan Bonus Karyawan dengan Menggunakan Metode Analytic Network Process di PT. Global Harvest Precision Engineering.

Journal of Engineering, Technology \& Applied Science, vol. 2, no. 1, pp. 51-58, April 2020. DOI: 10.36079/lamintang.jetas-0201.94

Setelah melakukan analisa data, selanjutnya adalah melakukan pengolahan data yang diperoleh dari pengumpulan data primer dan sekunder yang telah dilakukan pada tahap sebelumnya.

5. Perancangan Sistem

Data yang telah diolah kemudian didapatkan pengujian sistem dan diketahui apa kebutuhan yang diperlukan, sehingga penulis dapat melakukan perancangan

6. Pengujian Sistem

Pada langkah ini dilakukan untuk mengamati sejauh mana suatu sistem yang akan di bangun dan semua kebutuhan yang di perlukan, sehingga penulis dapat melakukan pengujian sistem

7. Implementasi

Setelah melakukan pengujian sistem, penulis melakukan evaluasi pengujian sistem untuk mengetahui data yang dibutuhkan telah memenuhi semua kebutuhan atau suatu sistem yang dibutuhkan dengan perancangan yang telah dibuat, jika tidak sesuai maka penulis kembali melakukan pengumpulan data kemudian melakukan pengolahan data kembali, namun jika perancangan yang telah dievaluasi sudah sesuai maka penulis ke tahap selanjutnya yaitu implemetasi sistem

8. Kesimpulan

Setelah sistem diimplementasikan, penulis mendapatkan kesimpulan dan sampai pada tahap selesai.

\section{Hasil dan Pembahasan}

\subsection{Hasil}

Penentuan Bonus Karyawan dengan Menggunakan Metode Analytic Network Process di PT. Global Harvest Precision Engineering yang membantu dalam pengambilan keputusan penerima bonus.

Pada rancang bangun sistem ini menghasilkan sebuah sistem pendukung keputusan yang mencakup kemampuan untuk membantu menilai dan membantu mengambuil sebuah keputusan berbasis web dengan menggunakan metode DFD (Data Flow Diagram), dimulai dengan pengumpulan data, analisa masalah, analisa sistem, perancangan sistem, perancangan DFD, perancangan database.

\subsection{Pembahasan}

Metode yang digunakan dalam penelitian ini adalah Model Analytic Network Process (ANP) dan menggambarkan skema laur sistem menggunakan Data Flow Diagram (DFD), dengan tahapan sebagai berikut:

1. Perancangan Sistem

Pada umumnya tujuan dari perancangan sistem informasi adalah:

a. Untuk memenuhi pemakaian sistem

b. Memberikan gambaran yang jelas dan rancangan yang lengkap kepada pemrograman komputer dan ahli teknik lainnya yang terlibat.

c. Perancangan sistem harus actual dan cepat untuk mendukung pengolahan data suatu kegiatan yang dilaksanakan.

2. Analisis Sistem

a. Analisa kebutuhan sistem bertujuan untuk menganalisis kebutuhan-kebutuhan dalam penggunaan sistem. Sistem informasi pada bidang pencegahan ini berbasis web dan menggunakan Database MySQL.

b. Analisa Sistem Berjalan

Untuk membuat sebuah sistem yang dapat mewakili dari sistem yang sudah ada serta dapat mengatasi dari kelemahan-kelemahannya maka perlu dilakukan analisa terhadap sistem yang lama, adapun analisa dari sistem yang lama adalah sebagai berikut:

1. Memeriksa data absensi karyawan setiap hari.

2. Menghitung menggunakan microsoft excel berapa kali karyawan tidak masuk, sakit dan izin maupun terlambat.

3. Menghitung berapa lama karyawan tersebut bekerja di PT. Global Harvest Precision. 
4. Memeriksa jumlah poin-poin karyawan yang dicatat oleh manajer yang diberikan setiap akhir bulan.

5. Setelah langkah satu (1) sampai dengan empat (4) dilakukan maka dikumpulkan menjadi satu dan siapa yang memiliki absensi bagus, paling lama bekerja di PT. Global Harvest dan memiliki poin tertinggi akan mendapatkan bonus lebih banyak dari pada yang lainnya.

\section{Perencanaan Sistem}

Perencanaan sistem ini bertujuan untuk mengetahui proses penilaian yang akan diusulkan untuk masa depan.

Analisa sistem baru dilakukan untuk menyusun langkah-langkah dalam mengidentifikasi permasalahan-permasalahan yang akan terjadi pada sistem yang akan dibangun. Serta kebutuhan-kebutuhan apa saja yang diinginkan untuk mengastasi permasalahan yang ada pada sistem nantinya dan dapat dijadikan sebagai alat bantu dalam pengambilan keputusan penentuan bonus karyawan. Sistem baru ini digunakan oleh Admin yang berfungsi untuk menetapkan nilai cluster dan subkriteria.

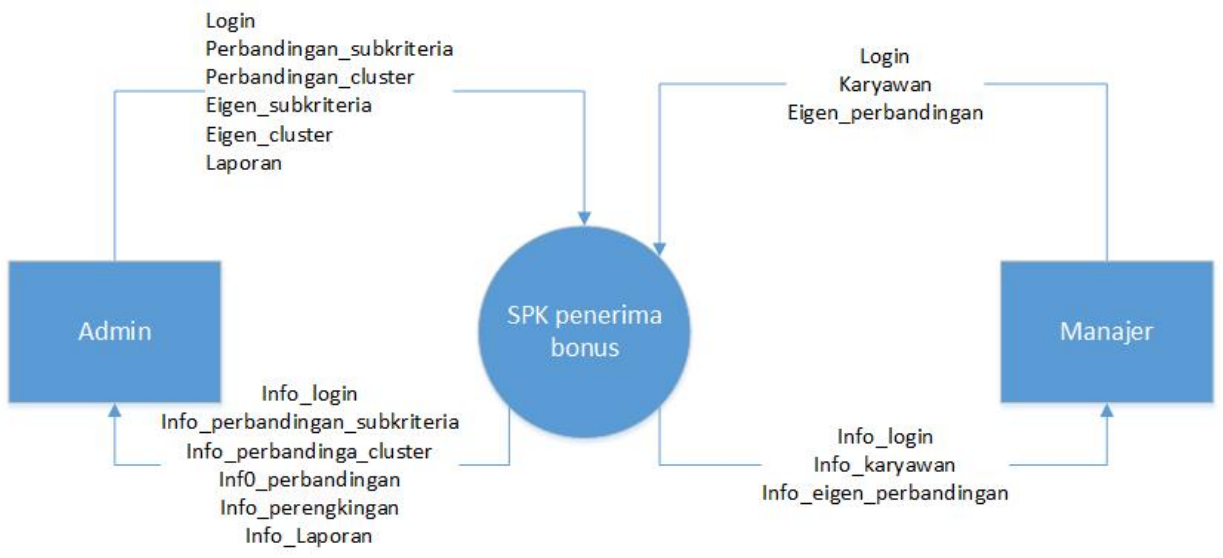

Gambar 1. Diagram Konteks

Keterangan:

Pada Gambar di atas diagram konteks terdiri dari 2 entitas, yaitu admin dan manajer. User dapat melakukan pengolahan setiap data yang ada pada sistem, sedangkan manajer memiliki hak akses lebih banyak dibandingkan user.

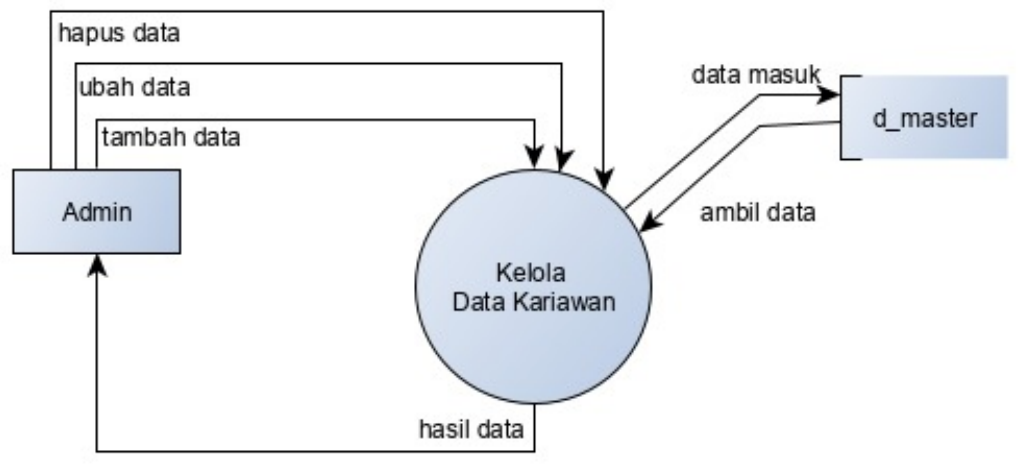

Gambar 2. Data Flow Diagram Level 1 
Suliza Apandi, Okta Veza, Sanusi Majid, Pratiwi, Ismail Yusuf Panessai.

Penentuan Bonus Karyawan dengan Menggunakan Metode Analytic Network Process di PT. Global Harvest Precision Engineering.

Keterangan:

Diagram level 1 menunjukan fungsi-fungsi atau suatu proses aliran data entitas, dan penyimpanan data yang dibutuhkan pada sistem yang diusulkan.

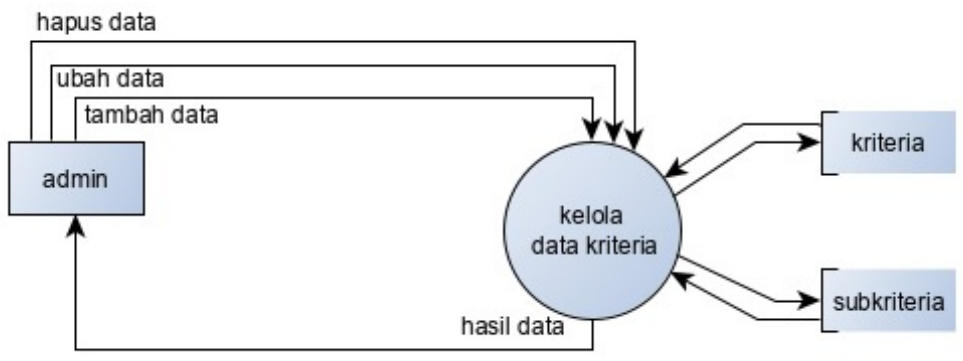

Gambar 3. DFD Level 2 proses 1.0 Pengolahan Data Kriteria

Keterangan:

Pada diagram level 2 proses 1.0 mendeskripsikan suatu proses pengolahan data kriteria.

Pada diagram level 2 proses 2.0 mendeskripsikan suatu proses pengolahan data kegiatan yang terdiri dari empat proses pada proses 2.1 menginput data kegiatan, pada proses 2.2 melihat data kegiatan pada proses 2.3 dan proses 2.4 seorang admin dapat merubah dah menghapus sebuah data.

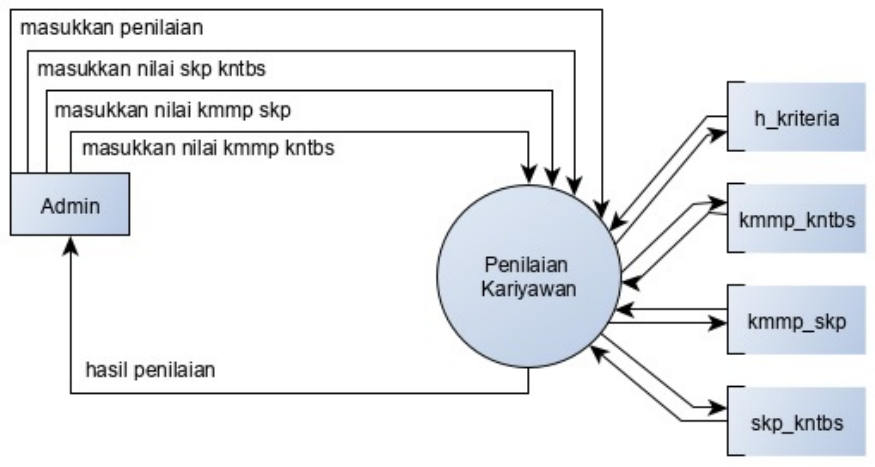

Gambar 4. DFD level 2 Proses 3.0 Penilaian Karyawan

Keterangan:

Pada diagram level 2 proses 3.0 mendeskripsikan suatu penilaian karyawan yang terdiri dari kriteria, subkriteria.

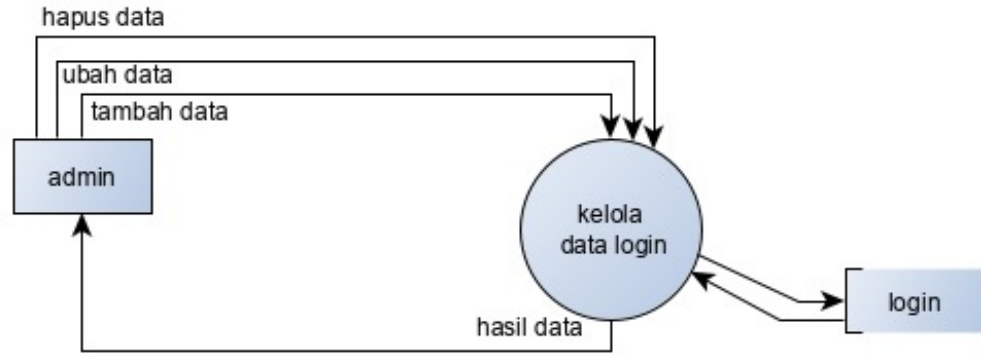

Gambar 5. DFD Level 2 Proses 4.0 Mengelola Data Login 
Suliza Apandi, Okta Veza, Sanusi Majid, Pratiwi, Ismail Yusuf Panessai.

Penentuan Bonus Karyawan dengan Menggunakan Metode Analytic Network Process di PT. Global Harvest Precision Engineering.

Journal of Engineering, Technology \& Applied Science, vol. 2, no. 1, pp. 51-58, April 2020. DOI: 10.36079/lamintang.jetas-0201.94

Keterangan:

Pada diagram level 2 proses 2.0 mendeskripsikan suatu proses pengolahan login.

4. Implementasi Sistem

Pada tahapan implementasi ini merupakan gambaran dari sistem yang telah di rancang, sebagai berikut:

a. Halaman Menu Login

\section{PT.GHPE}

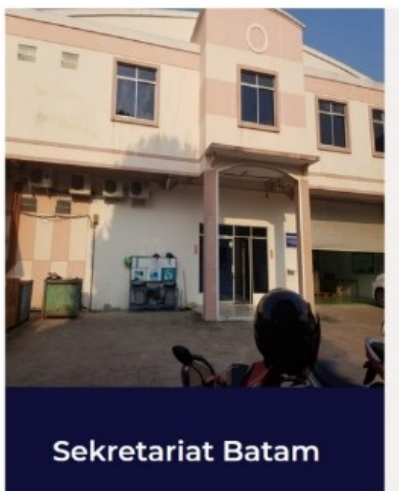

\section{PT. Global Harvest Harvest Precision Engineering}

\section{Gambaran Umum}

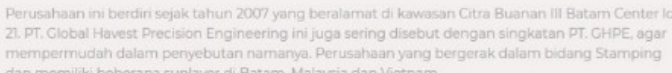

dan memiliki beberapa suplayer di Batam, Malaysia dan Vietnam

Gambar 6. Halaman Menu Login

Keterangan:

Halaman tersebut menunjukan halaman login yang mana admin harus memasukkan nama pengguna dan kata sandi. Jika nama pengguna dan kata sandi yang dimasukkan benar maka akan menuju ke menu halaman utama.

5. Halaman Menu Utama

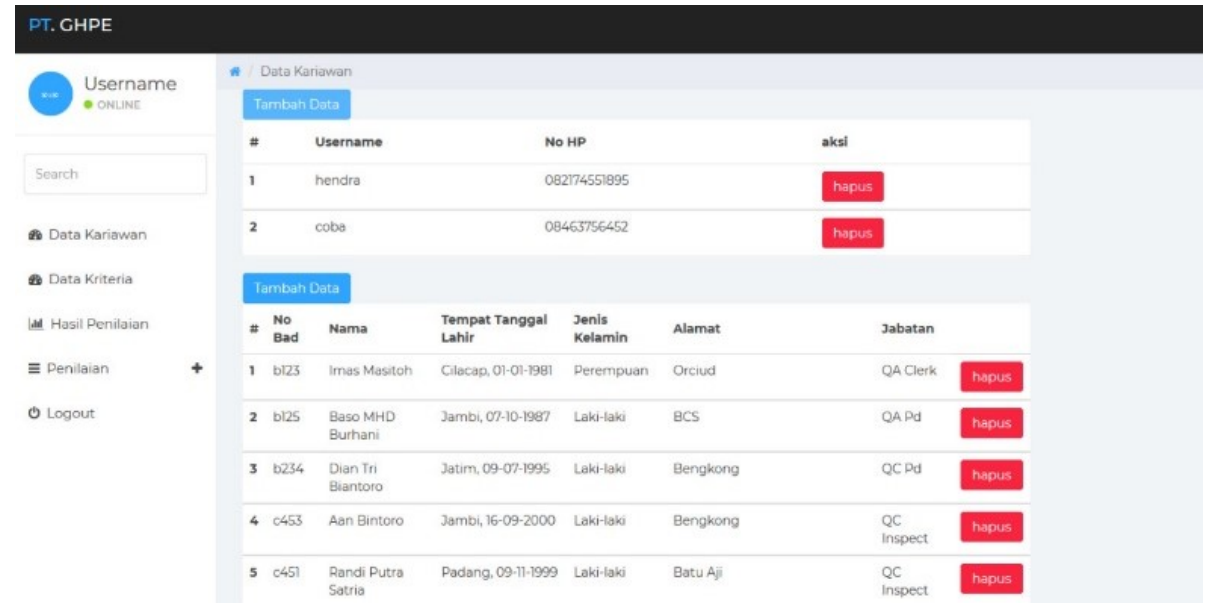

Gambar 7. Halaman Menu Utama 
Suliza Apandi, Okta Veza, Sanusi Majid, Pratiwi, Ismail Yusuf Panessai.

Penentuan Bonus Karyawan dengan Menggunakan Metode Analytic Network Process di PT. Global Harvest Precision Engineering.

Journal of Engineering, Technology \& Applied Science, vol. 2, no. 1, pp. 51-58, April 2020. DOI: 10.36079/lamintang.jetas-0201.94

Keterangan:

1) Gambar tersebut menunjukkan tampilan dari menu utama yang bersikan tabel admin yang yang bisa menggunakan sistem tersebut maka tidak semua orang bisa menggunakan sistem tersebut

2) Jika ingin mengubah data maka admin yang bisa melakukan pendaftaran seorang user, maka pilih pada menu seting dan masukkan data yang diinginkan.

3) Jika ada suatu user yang tidak bekerja lagi maka suatu user tidak bisa melakukan login pada sistem tersebut.

6. Halaman Menu Penilaian

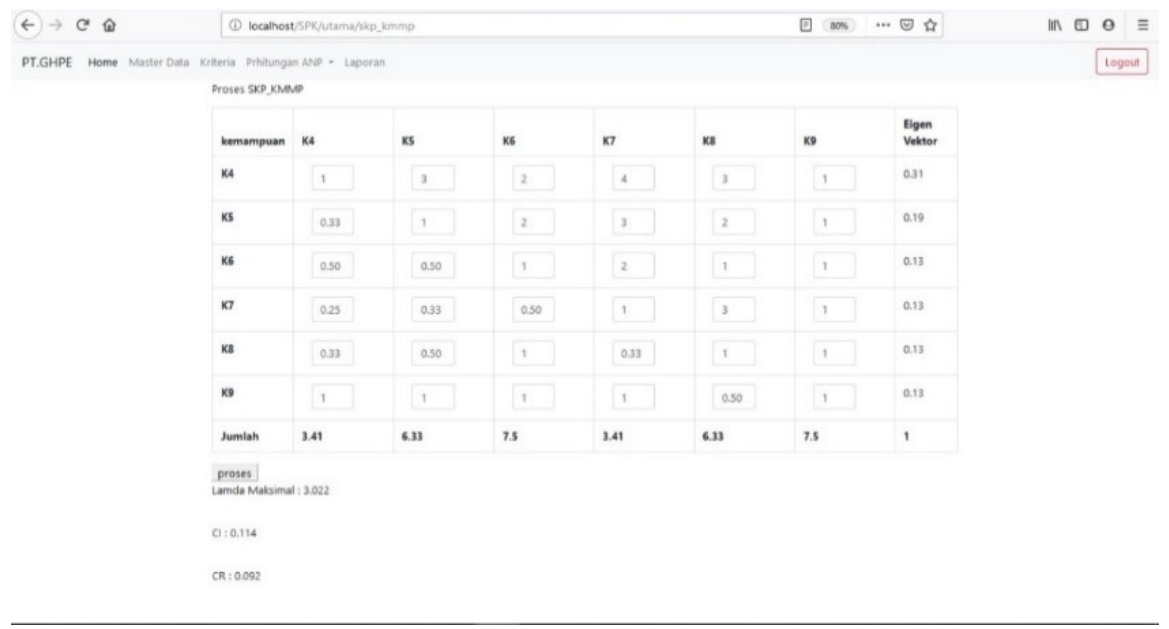

Gambar 8. Halaman Menu Penarikan Dana

Keterangan:

Gambar tersebut menunjukkan tampilan dari menu penilaian untuk karyawan yang akan diberi nilai.

\section{Kesimpulan}

Penentuan bonus karyawan dengan menggunakan metode Analytic Network Process ini, diharapkan dapat membantu suatu pekekerjaan staf PT. Global Harvest Precision Engineering dalam membantu dalam mengambil sebuah keputusan yang diperlukan, maka penulis menyimpulkan:

1. Sistem yang membantu dalam memberikan penilaian tentang beberapa kriteria dan subkriteria penilaian yang sudah ditentukan oleh PT. Global Harvest Precision Engineering, serta mampu memberikan kemudahan dalam memberikan sebuah penilaian dan mampu menyingkatkan waktu yang lama saat masih menggunakan sistem lama.

2. Sistem pendukung keputusan yang mengandung metode ANP, sehingga dapat memberikan penilaian yang lebih akurat dengan nilai konsistensi kurang atau sama dengan 10\% (0.1), sehingga dapat lebih akurat dalam penilaian pemilihan karyawan yang mendapatkan bonus.

\section{Daftar Pustaka}

[1] P. T. Pungkasanti, and T. Handayani, "Penerapan analytic network process (ANP) pada sistem pendukung keputusan," Jurnal Transformatika, vol. 14, no. 2, pp. 66-71, 2017.

[2] P. Astuti, "Pemilihan Supplier Bahan Baku dengan Metode AHP Study Kasus PT. Nara Summit Industry, Cikarang," Jurnal Teknologi Informasi dan Komunikasi, vol. 7, no. 1, pp. 3948, 2016.

[3] E. Darmanto, N. Latifah and N. Susanti, "Penerapan metode AHP (Analythic Hierarchy Process) untuk menentukan kualitas gula tumbu," Simetris: Jurnal Teknik Mesin, Elektro dan Ilmu Komputer, vol. 5, no.1, pp. 75-82, 2014. 
Suliza Apandi, Okta Veza, Sanusi Majid, Pratiwi, Ismail Yusuf Panessai.

Penentuan Bonus Karyawan dengan Menggunakan Metode Analytic Network Process di PT. Global Harvest Precision Engineering.

Journal of Engineering, Technology \& Applied Science, vol. 2, no. 1, pp. 51-58, April 2020. DOI: 10.36079/lamintang.jetas-0201.94

[4] R. A. Destari, "Sistem Rangking Pemanfaatan Susu Bayi Menggunakan Analytical Network Process (ANP)," Sisfotenika, vol. 6, no. 1, pp. 56-67, 2016.

[5] R. Govindaraju, and J. P. Sinulingga, "Pengambilan Keputusan Pemilihan Pemasok di Perusahaan Manufaktur dengan Metode Fuzzy ANP.” J. Manaj. Teknol, vol.16, no.1, pp. 1-16, 2017.

[6] S. J. Kuryanti, and N. Indriyani, "Penentuan Bonus Pada Karyawan Dengan Menggunakan Metode Analytic Network Process (Studi Kasus: PT. Asahimas Flat Glass, Tbk Jakarta).” Prosiding Semnastek, 2016.

[7] R. V. Palit, Y. D. Rindengan, and A. S. Lumenta, "Rancangan Sistem Informasi Keuangan Gereja Berbasis Web Di Jemaat GMIM Bukit Moria Malalayang." Jurnal Teknik Elektro dan Komputer, vol. 4. No.7, pp. 1-7, 2015.

[8] A. M. Sari, and L. Yulianti, "Aplikasi Pendataan Pasien Rujuk Balik Peserta Badan Penyelenggara Jaminan Sosial (Bpjs) Bengkulu.” Jurnal Media Infotama, vol. 11, no. 2, 2015.

[9] N. Mursalin, and R. Ishak, "Sistem Pendukung Keputusan Pemilihan Duta Mahasiswa Generasi Berencana Bkkbn dengan Metode Weighted Product: (Studi Kasus pada Kantor Bkkbn Provinsi Gorontalo)." ILKOM Jurnal Ilmiah, vol.9, no.3, pp. 301-308, 2017.

[10] R. Nuraini, "Desain Algorithma Operasi Perkalian Matriks Menggunakan Metode Flowchart," Jurnal Teknik Komputer, vol. 1, no. 1, pp. 144-151, 2015. 